\title{
Job Satisfaction, Motivation and Performance at Self-Managing Teams
}

\author{
*Besnik Avdiaj, "*Besime Ziberi \\ * Management and Informatics, University of Prishtina, Prishtina 10000, Kosovo, \\ Republic of Macedonia \\ ** AAB College, Industrial Area Prishtina-Fushe Kosova, 10000, Kosovo, \\ Republic of North Macedonia
}

Corresponding author: besnikbavdiaj@gmail.com

\section{ABSTRACT}

Self-managing teams have occupied the modern organizations. Even though it is still in its commencement, the theory of self-managing teams is developing with fulminant steps towards imposing this philosophy to most of the organizations operating in dynamic environments. Thus, studying these semi-autonomous or entirely independent formations is particularly important in order to follow the global trends of management. In this spirit, this study discusses some human aspects which are influenced by self-managing philosophy, respectively it analyses the relationships between team self-management and job satisfaction, motivation and perceived performance. This is supported theoretically by a bunch of studies which discuss predictive elements for creation of self-managing teams, the outcomes as a result of team self-management and others that discuss both inputs and outcomes. Respondents were surveyed through selfreporting questionnaire, comprising of several instruments tested in previous studies. 55 respondents of 19 entrepreneurial start-up teams have been surveyed. According to the results calculated through SPSS, it is confirmed that team self-management is positively related to job satisfaction and perceived performance of team members. However, from regression and correlation analysis, it appears that there is no stable relationship between team selfmanagement and motivation.

Keywords:

team self-management, job satisfaction, motivation, performance. 


\section{INTRODUCTION}

Several studies have been made on organizations and organizational structures. The nature of studies is interdisciplinary, but the main field which treats the organizational dynamics, is the managerial one. The new course of management has led to experimenting with different structures of people and today we have a diversity of models in organizations. On top of that, a very recent topic has been blowing the minds of entrepreneurs, managers and researchers - self-managing teams.

Since ' 80 s there has been discussed an interesting aspect of teams, which is a nonconventional approach of management and is defined as a self-managing philosophy. It is about teams having some characteristics which essentially differ them from the 'traditional' teams, in terms of assigning tasks, management, monitoring, rewarding and other elements, which in general are supposed to be set by hierarchical positions at 'traditional' structures. These characteristics come up as a self-managing perspective, a developed concept especially in the last 30 years, mainly as a result of experiments in different companies.

Based on some questionnaires, it is found that $79 \%$ of companies listed in Fortune 1000, use this type of 'empowered', 'selfdirected' or 'autonomous' teams (Druskat \& Weheeler, 2004). Those companies basically made changes in terms of delegating to teams, the decision-making authority, tasks assignment, controlling and rewarding processes. Hence, although it can be supposed that self-managing teams have existed earlier, the scientific approach on them dates pretty late, with the first publications in '50s-'60s, and later on at the end of 'ros and '80s. However, an incre- dible number of studies has been realised since the '90s, discussing different selfmanaging teams facets.

\section{LITERATURE REVIFW}

Teams have long received the attention of scholars of various sciences, but also of the business community, that of public administration and public opinion in general. As a fairly modern concept, teams are characterized as group formations, so they are part of the second level of the organizational plan.

First, let's have a look at some comparisons between the three levels of the organization: the individual, the group, and the organization itself. While the individual represents a unique human being with characteristics that differ from the other person (Schermerhorn Jr., et al., 2010; George \&e Jones, 2011; Schermerhorn Jr., 2014), the group is a union of individuals who through their actions and reciprocal influence on each other, are committed to achieving certain tasks and a specific goal. (Champoux, 2011; Robbins \& Judge, 2013). Both the individual and the group are simply constituent elements of a "supraindividual" and "supragroup" formation that we call an organization. Many scholars agree that it represents a structure of positions, command line chain, hierarchy of authority and control, a certain degree of de/ centralization, uses certain technology and coordinates tasks between different groups and departments (Schermerhorn Jr., et al., 2010; Schermerhorn Jr., 2014; George \&e Jones, 2011; Robbins \&e Judge, 2013).

Authors have given different definitions about the team, where in his Bachelor's degree thesis, Avdiaj (2017) has analysed 
the role of team size in decision-making and found that according to Schermerhorn Jr. (2014), a team is a small group of people who perform certain tasks within the organization, where team members have complementary skills and are mutually responsible for their actions. Findings of Schermerhorn Jr. (2014) are also supported by R. Daft (2008), who considers the team as a group of 2 or more members who coordinate their activities to achieve a common goal and also have a sense of sharing the same mission with each other.

In the "Group Dynamics" book, the fifth edition it is stated that "despite this diversity in terms of focus, composition, and design, teams are fundamentally groups, and so they possess the basic characteristics of any group: interaction, goals, interdependence, structure, and unity" (Forsyth, 2010, p. 353). Yet there is something that makes the teams to be essentially different from the groups. Forsyth (2010, p. 353) states that “... what sets teams apart from other groups is the intensity of each these attributes within teams." So, in a broader sense, for each of the characteristics that teams share with groups, the increased intensity of these characteristics makes these groups to be considered as teams. Increased interaction, stronger cohesion among team members, mutual influence of achievement, and task outcomes are some of the features set in a more intensive plane that make the teams what they are.

Thus, teams are group formations, where members are closely related, have a clear purpose, open communication, participation, informal relationships, reciprocal interactions, style diversity and self-esteem (Mealiea \& Baltazar, 2005). As stated above, we can conclude that the definition of teams is appropriate to groups in different fields, who perform different functions and tasks or are part of different projects. However, they should basically have the above mentioned characteristics.

Sundstrom, et al. (2000, as cited at Kozlowski \&e Bell, 2003) have generalized some classifications of teams in the following categories: a) production, b) services, c) management, d) project, e) realization, and f) and consulting (Sundstrom, et al., 1990, Cohen \& Bailey, 1997, as cited in Kozlowski \& Bell, 2003). We also have some team classifications based on the cultural aspect (intercultural teams, mixed cultures and transnational teams) (Earley \& Erez, 1997, as cited in Kozlowski \& Bell, 2003). Kozlowski and Bell (2003, p. 9) have also found that we have virtual teams, which are differed by traditional "face-to-face" teams because they perform their tasks without physical presence in the common workplace.

According to Hackman's suggestions (1986), organizational units (teams) with a high level of self-management may and should be considered as alternative models to traditional management patterns within organizations. This has led other researchers to analyse different aspects of self-managing teams. In theory, we can find them as self-leading teams, self-designing teams or self-governing teams, but basically, the common of these concepts is the overall management by team members themselves.

Self-managing philosophy can be defined as a concept that involves the diversity of skills and capabilities of group members 
(Hackman, 1976; Wall, et al., 1986, as cited in Cohen \& Ledford Jr. Jr., 1994); group autonomy to determine task execution (Hackman, 1976; Hackman, 1986), work planning and team design, undertaking actions on different issues, collecting and analysing information and accomplishing organizational goals (Hackman, 1976; Hackman, 1986; Goodman, et al., 1988; Wellins, et al., 1990; van der Vegt, et al., 2010). These teams decide on their behaviour or define entirely their work (Cumming \& Griggs, 1977, Goodman, et al., 1988, as cited in Cohen \&e Ledford Jr. Jr., 1994). Thus, from "self-managing" epithet itself, it is clear that these organizational units manage themselves (Stephens \& Luddy, 2016), comparing to other units with traditional hierarchy that are managed from external members, as explained by Lawrence and Lorsch (1967).

According to Hackman (1976, p. 3), a self-managing team includes a work design as following: "1. A "whole" task for the group (...); 2. Workers who each have a number of skills required for the completion of the group task (...); 3. Autonomy for the group to make decisions about the methods of carrying out the work (...); 4. Compensation and feedback about performance based on the accomplishments of the group as a whole (...)." These characteristics have later been discussed by other scholars, by adding the processes of work planning, actions towards problem solutions, gathering information and meeting organizational goals (Goodman, et al., 1988; Wellins, et al., 1990).

Self-managing teams are no less than a group of individuals who, above all, interact with each other. In this way, scholars of different fields have conducted researches over a considerable number of team aspects in self-managing perspective.

Studies have proven that in general, there is a positive relationship between team self-management and other variables, like team effectiveness, empowerment, innovativeness, motivation, job satisfaction and productivity (Viehhauser, 2010; Millikin, et al., 2010; Muthusamy, et al., 2005).

In most of the cases, successful implementation of self-managing teams has produced positive effects in job satisfaction of team members (Elmuti, 1997). On the other hand, Yang, Guy (2011) and Renkema, et al. (2018) offer contemporary evidence that members of self-managing teams enjoy higher levels of job satisfaction. In addition to this, Politis's (2006) evidence demonstrates that self-managing teams apart from increasing the level of job satisfaction are also beneficial in terms of a team's performance.

Some studies have also incorporated the component of leadership as a debatable element of self-managing teams. Nevertheless, in regard tojob satisfaction, Elloy (2005) contends that the presence of a superleader positively affects job satisfaction, whereas Solansky (2008) while analysing the functioning of shared leadership in these types of teams, he suggests that job satisfaction is higher as a matter of this leadership.

Van Mierlo, et al. (2005) have analysed a total of eighteen empirical studies, among which thirteen do include the dimension of job satisfaction of self-managing teams. 
Nine out of these thirteen studies show that team self-management has positive relations with job satisfaction, meanwhile in three of them, it is evidenced that there are no relations between these two variables. Only one study shows that this relation is rather negative (Van Mirelo, et al., 2005). In light of the above, we can formulate a logical presumption, as a hypothesis that self-managing philosophy positively affects job satisfaction. This is supported by Viehhauser (2010), in his comparison of the data of selfmanaging teams' members with those of traditional teams. In this very same study, Viehhauser concludes that selfmanaging teams offer their members more motivation, job satisfaction and empowerment.

Vragelaar's (2017) model demonstrates that motivation is related with group processes and work design, by increasing in this way the work life quality. In the work conducted by Van Mierlo, et al. (2005), it can be noted that out of 18 studies, 6 have referred to motivation as an outcome of self-managing teams. These facts provide us with a sufficient reason to investigate motivation as a product of self-managing philosophy in teams.

Theory provides us with many studies regarding different aspects of the performance of self-managing teams. While some studies have evaluated the productivity of self-managing teams, others have focused on effectiveness. In principle, these two terms can and will be used interchangeably, as performance is measured by how much is a team productive, effective or successful.

It is considered that self-managing teams are more effective than traditional ones
(Cohen \&e Ledford Jr., 1994) and they generally have a positive effect in a team's overall performance (Elmuti, 1997; Elmuti \& Kathawala, 1997). Glassop (2002) argues that self-managing teams have greater productivity, smoother management structure and lower turnover. In this respect, Millikin and colleagues (2010) suggest that using selfmanaging teams in multi-team systems, has many benefits in productivity.

Nonetheless, there are many other factors that affect the performance of self-managing teams. In this way, some authors suggest that self-managing teams need to cultivate the culture of team thinking in order to avoid the consequences of group thinking that can emerge in a team (Neck \& Manz, 1994; Manz \& Neck, 1995). Others are of the opinion that performance is related with the strong belief in situations when individual autonomy is low (Langfred, 2004) and with the extroversion of team members (Barry \& Stewart, 1997). Job satisfaction (Politis, 2006) and team work (Yang \& Guy, 2011) can have a positive impact in the high performance of these teams. As pertains the environment where self-managing teams develop, Tata's and Prasad's (2004) observations show that this kind of team best develops in organizational settings with fewer rules and procedures. On the other hand, Kirkman and Shapiro (2001) contend that collective culture positively impacts the performance of self-managing teams.

\section{METHODS}

This research was conducted in a startup setting with self-managing teams, respectively entrepreneurial teams which have already established or have been in the process of establishing a start-up. 
These teams were investigated in several organizations, such as Innovation Centre Kosovo, Jakova Innovation Center, Venture-UP and Makerspace Innovation Center Prizren.

\section{Sample and data collection}

These teams have been identified in communication with the organizations. The survey is conducted through a structured questionnaire. Attempts have been made to involve as many members of these teams as possible in order to have a representative sample. Having encountered great difficulties in contacting the teams and conducting the survey with their members, in some cases data were also collected through online questionnaires and several entrepreneurial teams were also investigated outside the above mentioned organizations.

In total, 55 members of self-managing teams were surveyed (responses rate was $65 \%$ of the 85 total members of these teams), distributed in 19 teams. The average number of members per team is around 4.5 members.

\section{Measures}

The data were collected through an individual-level survey. The questionnaire was compiled using scales from scientifically tested instruments in previous studies. These are adapted and translated and adjusted from English to Albanian. Compounding parts of this questionnaire are further explained as following.

A note should be made at this part: considering that this paper derives from the Master thesis (Avdiaj, 2019), the focus has been put only on the aspects of interest, thus not discussing the demographic aspect of the respondents.

Team self-management level - The questions used in this section aim to measure the level of self-management in the entrepreneurial teams. This is to establish the initial assumption that entrepreneurial teams can be considered as models for analysis similar to selfmanaging teams. Questions have been adapted from Campion, et al. (1993 \& 1996), Langfred (2005), Leach, et al. (2005), Groeneveld and Kuipers (2014), and van der Hoek, et al. (2018).

Job satisfaction - Since the scope of the research is to measure the impact of team self-management in three variables, including job satisfaction, and then the questions in this section are adapted from the Job Diagnostic Survey - JDS of renowned scientist Richard Hackman and Greg Oldham (1975).

Motivation - Measurement of motivation was based on the study of Viehhauser (2010), who adapted the instrument from Ray (1979), respectively by Job Diagnostic Survey - JDS (Hackman \&e Oldham, 1975). To measure the motivation are listed 14 statements, for which the respondent's rating from 1 (Disagree strongly) to 7 (Agree strongly), according to Likert scale.

Perceived performance - For performance measurement, we have found in some research that self-reporting questionnaires have not been sufficiently effective compared to observational methods that have emerged to be more consistent in team performance assessment (Anderson, et al., 2017), but depending on the nature of the study, it is suggested to create a measure of 
perceived performance measurement by the author himself. Therefore, a scale for measuring the perception of performance by the members of these teams has been compiled, trying to be relatively appropriate for our case. This self-developed instrument has a high degree of reliability according to this study (Cronbach's Alpha 0.74), where it is suggested to be tested in other similar cases to verify whether this instrument can be applied to produce results in other studies as well. This instrument contains 10 statements, which are evaluated by respondents at Likert scale from 1 (Disagree strongly) to 7 (Agree strongly). The data were analysed through SPSS and two analyses were conducted: linear regression and correlation.

\section{RESULTS}

The computation of averages for the relevant instruments has been made in SPSS, so that analysis of regression and correlation could be executed. Thus, for self-management the level, the average of responses of each respondent for 10 requests of the measuring instrument of team self-management is computed. The same was done with other variables: for job satisfaction, the arithmetic average of 14 responses was computed; for motivation, the arithmetic average of 14 responses was computed; as well as for the perceived performance, the arithmetic average of 10 responses was computed.

\section{Team self-management}

From the descriptive analysis of team self-management, the respondents stated a high level of team self-management, respectively above 2.77 / 5.00, with an added concentration between 4.00 and 5.00. More specifically, the average for team management alone is 4.196, with a standard deviation of .61 and a variance of .372, which can be interpreted as a confirmation of the initial assumption that entrepreneurial teams in any of the stages of startup development can be considered as an appropriate model for conducting research regarding the selfmanaging philosophy. This also suggests that these teams could be used as a model for further analysis of team selfmanagement.

\section{Job satisfaction}

Based on descriptive analysis of job satisfaction, it turns out that respondents are generally very satisfied. Expressed in numeric values, this variable has an average of 5.88, with a standard deviation of 1.05 and a variance of 1.11 .

\section{Motivation}

Respondents have generally declared a high level of motivation, though for 0.33 lower than job satisfaction. Specifically, the average of this variable is 5.5 with a standard deviation of .87 and variance .77.

\section{Perceived performance}

Although as a self-formulated question instrument, where reliability analysis is the lowest among instruments (Cronbach's Alpha =.74), respondents have generally declared a high level of performance. The average rate ranges to 5.69 (higher than job satisfaction and motivation), with a standard deviation of .75 and variance .56 .

\section{Regression analysis}

Regression analysis is conducted by measuring the impact of team selfmanagement on each of the variables separately. Therefore, Figure 1 shows 
the relationship between the level of selfmanagement in the team and the level of job satisfaction of the members of the self-managing teams.

As shown in Figure 1, team selfmanagement and team members' job satisfaction have a positive linear relation. Hence, with the growth of one unit in team self-management, job satisfaction increases for $.74 \mathrm{x}$ units, starting at a fixed level of 2.7\%. From this result we can conclude that self-managing philosophy in the team has a positive impact on increasing job satisfaction.

Next, we will see how team self-management influences the level of motivation of team members.

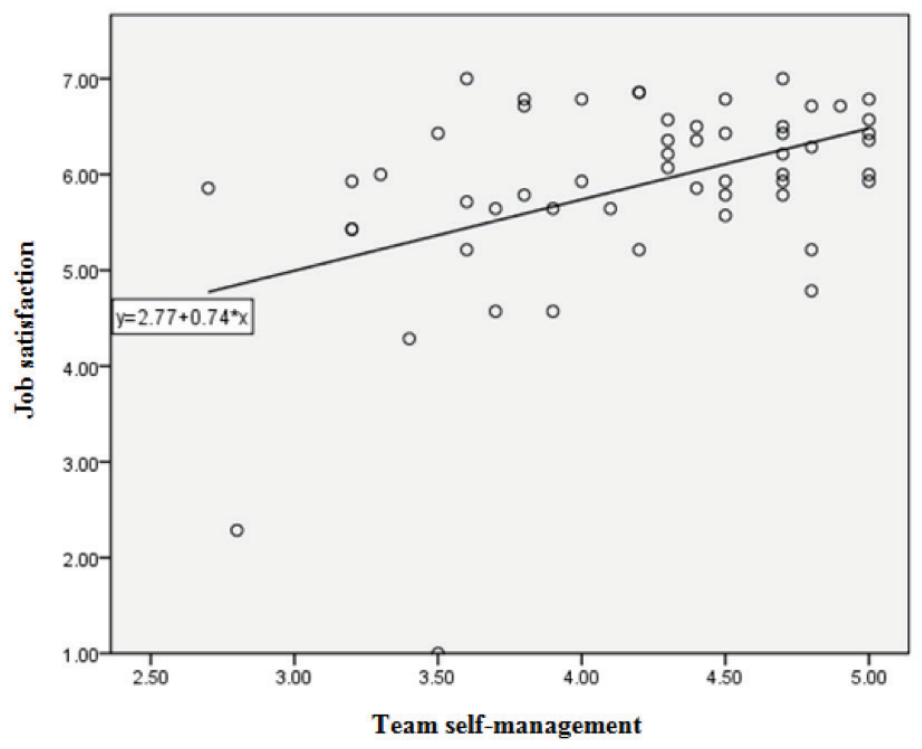

Figure 1. The influence of team self-management on job satisfaction

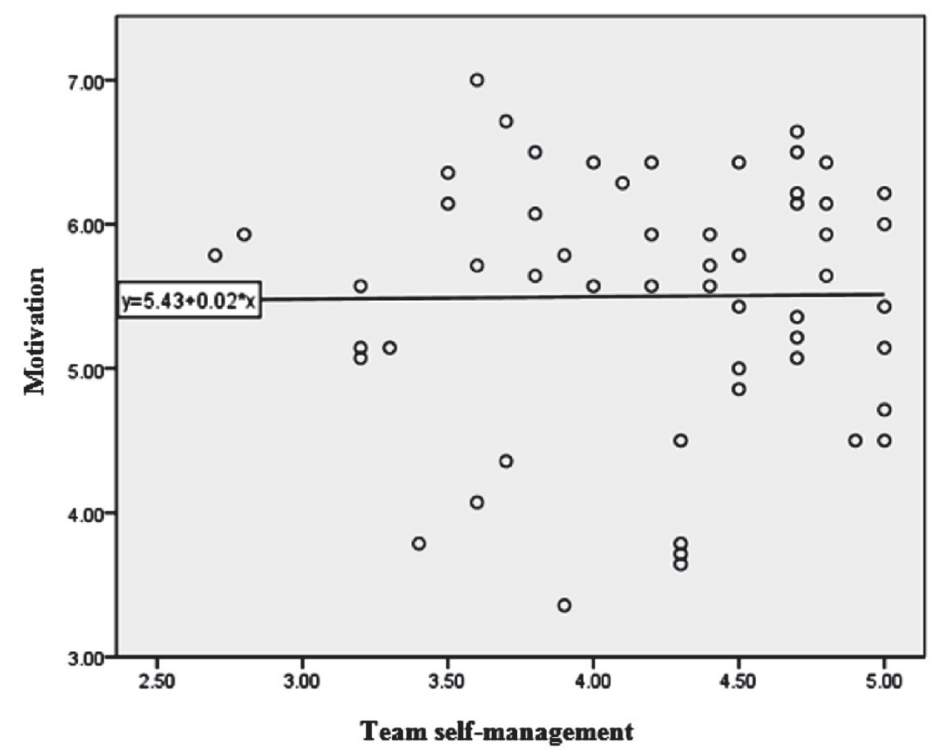

Figure 2. The influence of team self-management on motivation 
With an almost horizontal linear link, it seems that the self-managing philosophy does not have a major role in the level of motivation of team members. Specifically, with the growth of one self-management unit, motivation increases by only 0.02x. Through correlation, we will see the level of strength of this relationship is, although it has a slightly positive trend.

According to Figure 3 we can conclude that the self-managing philosophy positively influences the perceived performance by the members of the self-managing teams. Although in contrast to the level of impact on job satisfaction, there is less impact on performance perception, yet it can be estimated that for each unit that team self-management increases the perceived performance is increased by $0.24 \mathrm{x}$, which is a considerable value. This link is linear positive.

From the above, through the linear regression analysis, we have produced interesting results, which are also supported by the reviewed literature.

\section{Correlation analysis}

Through linear regression analyses between team self-management and three other conceptual variables, it was found that in all three cases the links are positive linearly. So, team selfmanagement solely influences each of the dependent variables. However, although in two cases (linear regression of team self-management with job satisfaction and team self-management with perceived performance), there is a clearer slope, resulting in a stronger positive correlation, and the same does not apply to linear regression between team self-management and motivation. Therefore, wanting to clarify the level of strength of this relationship, but also the other combinations in order to test the hypotheses, a correlation analysis has been carried out between these variables.

From Table 1 we can see that the findings from regression analysis are fully supported, even the strength of the links for each combination of variables is expressed more accurately. The following

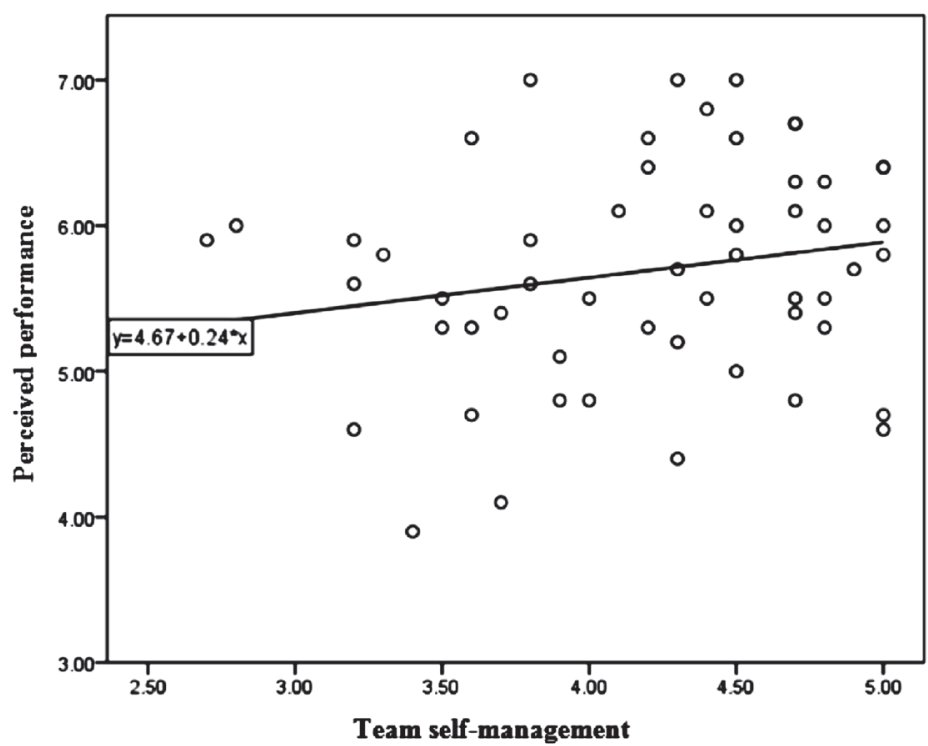

Figure 3. The influence of self-managing philosophy on perceived performance 
Table 4. Estimated Results of Generalized Method of Moment (GMM)

\begin{tabular}{lcccc}
\hline & $\begin{array}{l}\text { Team self- } \\
\text { management }\end{array}$ & Job satisfaction & Motivation & $\begin{array}{l}\text { Perceived } \\
\text { performance }\end{array}$ \\
\hline $\begin{array}{l}\text { Team self- } \\
\text { management }\end{array}$ & 1 & & \\
\hline Job satisfaction & $.430^{* *}$ & 1 & 1 & \\
\hline $\begin{array}{l}\text { Motivation } \\
\begin{array}{l}\text { Perceived } \\
\text { performance }\end{array}\end{array}$ & .011 & .081 & $.402^{* *}$ & 1 \\
\hline
\end{tabular}

explains the correlations for six combinations of variables:

Team self-management and job satisfaction - The link between team self-management and job satisfaction is positive and strong (up to the Pearson correlation coefficient level $=.430$ ).

Team self-management and motivation Just as it was seen by the linear regression between team self-management and motivation, the relationship is positive, but with a very weak strength, respectively we can say that the link between team self-management and motivation of team members is so pale as to scratch (so there is almost no slope). Here, too, this connection is proved to be weak, though positive (Pearson correlation coefficient $=.011$ ). The numerical values of the correlation coefficient between -0.1 and +0.1 can be interpreted as having no correlation between the variables, so in our case we can say that team self-management does not influence the motivation of team members.

Team self-management and perceived performance - The relation between these two variables is positive with a slight strength up to the Pearson coefficient = .198.
Job satisfaction and motivation - These two variables have a positive relation, with a slight strength, reaching Pearson $=.081$.

Job satisfaction and perceived performance - These variables have a relatively strong positive relation. The strength of the relation is expressed by the Pearson correlation coefficient $=.374$.

Motivation and perceived performance The ratio between these two variables is positive with a strong link, which reaches Pearson $=.402$.

\section{DISCUSSION}

Several studies have treated job satisfaction as an outcome of team self-management. Based on these studies, in almost all cases it has come out that job satisfaction is positively related to team selfmanagement (Elmuti, 1997). Even considering the recent evidence, we can see that members of the self-managing teams have high levels of job satisfaction (Yang \& Guy, 2011; Renkema, et al., 2018). Van Mierlo and colleagues (2005) found that in 9 out of 13 empirical studies where the relationship between team self-management and job satisfaction is analysed, this relation is positive, in 3 cases it does not exist, whereas in only one case it has been shown as a negative link. 
Even the results from this research suggest that the link between the 'team selfmanagement' variable and the 'job satisfaction' variable is linear and positive, even at a high degree of strength (Pearson correlation $=.430$ ). In his study, Viehhauser (2010) also reinforces this finding by making a comparison of job satisfaction among members in self-managing teams and those in teams with traditional structures.

Although it was expected that motivation would have a positive link with team selfmanagement (Hypothesis 2), such a result from the findings of the study would not be correct. From the very beginning it has been clarified that the amount of studies that treat motivation as an outcome of team self-management is relatively small, so the purpose of this research was to look at the effect that this philosophy has on the motivation of team members. Unlike this study, Viehhauser (2010) suggests that team self-management has a positive relationship with motivation, just as with job satisfaction and empowerment. However, his findings somewhat contradict the findings of Van Mierlo, et al. (2005), who among the 18 reviewed studies have found that only six of them have dealt with motivation as a result of team self-management. From these six studies, only two of them have been shown to have a positive relationship, whereas in four studies there was no link between these two variables. These findings of Van Mierlo, et al. (2005) are also supported by this research. Nevertheless, a wider tillage is suggested to address the motivation among members of these teams with the aim to have a clearer idea of the trend of results on how the self-managing philosophy affects their motivation.
Built hypotheses also include the positive impact of self-managing philosophy on performance. But, as explained by Anderson, et al. (2017), while performance assessment is mainly done by observational methods and referring to the numerical values of the organization, it was decided to measure performance from the point of view of the respondents, respectively the members of the self-managing teams, thus being considered as perceived performance. In other words, this can be called productivity, effectiveness, success, achievement, but in our case we will use only the performance label.

Thus, from previous studies it is suggested that self-managing teams generally have high performance (Elmuti, 1997; Elmuti \& Kathawala, 1997), and even compared to traditional teams, self-managing teams are more effective (Cohen \&e Ledford Jr., 1994). Glassop (2002) and Millikin with colleagues (2010) also suggest that self-managing teams have higher productivity. It is interesting to note that performance in self-managing teams is also influenced by job satisfaction (Politis, 2006), which is also reinforced through Table 4, where we have a relatively strong positive correlative link with a Pearson correlation coefficient $=.374$. In some studies, the performance of selfmanaging teams has been linked with increased organizational commitment and reduction of turnover, which has been identified to be effective (Park, 2012). Even in this study, although with a not very strong correlation (Pearson correlation coefficient $=.198$ ), we can conclude that there is a consistency of findings in relation to earlier studies, so the self-managing philosophy positively influences the perceived performance. 


\section{Reliability, validity and replicability}

Since in a scientific methodology it is estimated that a successful study involves three key criteria: reliability, validity and replicability (possibility of repetition), then through the results we can state that:

1. Reliability is high - the reliability or internal consistency analysis for each of the instruments used indicates a level significantly higher than 0.5.

2. The study is valid - this is explained by the regression analysis (Diagram 4, Diagram 5, Diagram 6 and Table 4), where we have the influence of a conceptual variable (self-managing philosophy) on other conceptual variables except motivation.

3. Reproducibility or possibility of repetition exists - the very fact that a method with instruments tested in previous studies is used, is sufficient to ascertain that such work can be repeated. This is reinforced with convincing results, among other things, high consistency in the use of the self-management instrument in entrepreneurial teams, giving us a clear message that not only can this work be repeated but similar researches can also to be conducted.

In this way we can conclude that the results of the study are reliable and valid, and the study is repeatable.

\section{Hypothesis testing}

This may be the most essential part of this study. Referring to the above results we will see how the hypotheses have been tested.

Hypothesis 1 - H I

The first hypothesis is formulated as following:

Hl. Self-managing philosophy has a posi- tive relationship with team members' job satisfaction.

From the results obtained through the linear regression analysis (Figure 1) and the correlation between self-managing philosophy and job satisfaction (Table 1), we can conclude that $\mathrm{Hl}$ is tested positively. So, the self-managing philosophy has a positive relationship with the team members' job satisfaction.

\section{Hypothesis 2 - H2}

The second hypothesis is formulated as following:

H2. Self-managing philosophy has a positive relationship with team members' motivation.

Referring to the linear regression analysis (Figure 2) and the correlation between self-managing philosophy and motivation (Table 1), we can conclude that H2 has not been tested positively. So, the self-managing philosophy has no relation with motivation of team members (neither positive nor negative link).

In this case, we can do an H2 reformulation, as following:

H2.O - Self-managing philosophy does not affect the motivation level of team members.

Hypothesis 3 - H3

The third hypothesis is formulated as following:

H3. Self-managing philosophy has a positive relationship with the perceived performance of team members.

This hypothesis is tested positively, because the linear regression according to Figure 3 and the correlation coefficient according to Table 1 suggest that self- 
managing philosophy is positively correlated with the perceived performance of team members. Thus, the higher this level of team self-management, the team members will evaluate the performance at higher levels.

\section{Hypothesis 4-H4}

For the fourth hypothesis we had the following formulation:

H4. Job satisfaction, motivation and performance in self-managing teams, have strong positive relationships.

For the fourth hypothesis, we can say that it is partially tested. If we refer to Table 1 , we can see that besides the links between team self-management and motivation as well as motivation and job satisfaction, all other links are positive relatively strong (nay the self-management and job satisfaction reach the Pearson correlation coefficient $=.430$ ). From this we can fragment the fourth hypothesis into several sub hypotheses, according to the tests:

H4.1 - Team self-management and job satisfaction have a positive strong relation.

H4.2 - There is no relation between team self-management and motivation.

H4.3 - Team self-management and perceived performance have a positive slightly strong relation.

H4.4 - There is no relation between job satisfaction and motivation.

H4.5 - Job satisfaction and perceived performance have a relatively strong positive relation.

H4.6 - Motivation and perceived performance have a positive strong relation.

So, as seen above, all the hypotheses have been tested, with some results differing from the original hypothesis (i.e. motivation).

\section{Limitations}

Limitations are an integral part and unfortunately inevitable in any research. Price and Murnan (2004) suggest that the explanation of limitations helps researchers, but also the audience and other scholars, to better understand the nature of the study and the issues presented, so in other cases in the future, the same ones might be minimized.

Even in this case, it has been proved that during the development of the study some limitations have emerged, mainly of theoretical and human nature, as following:

1. Literature review. According to research results, there were a relatively large number of studies on selfmanaging teams, but many of them were considered unnecessary for analysing, referring to the titles and abstracts. This limitation, based on a logical bias, may have had a considerable impact on the dissemination of some genuine studies in this field.

2. The inability of full access to scientific literature. This is a limitation of the technical nature, which has greatly limited the achievement of the maximum in the conduct of the study. Because many of the studies considered appropriate for theoretical review were not accessible on some platforms or were accessible in exchange for a purchase fee payment, we were limited to examining studies which we managed to download free of charge.

3. Result bias. Most researchers when starting a scientific research have a clear idea to some extent about what they are looking for. This intuition can influence the whole course of the research. However, in many cases, such bias can be discarded either by 
theoretical results or by field results. In the case of this study, although we expected that members' motivation would have a positive relationship with team self-management, this was not confirmed.

4. Start-up setting. Taking into consideration the lack of information on organizations which have self-managing teams in their structures, we took the risk of exploring these structures in start-up setting. This might be the first study which examines such teams in this setting, which basically arise the recommendation for future research in this field.

However, despite the aforementioned limitations, this research is a modest contribution in many aspects: in theory of teams, respectively self-managing teams, and in particular creates empirical basis for future researches in this field in Kosovo.

\section{CONCLUSIONS}

Self-managing teams have become imperative in many companies and organizations. Traditional management theories are being questioned by recent findings in this area, and we can freely consider that organizational behaviour has been the focus of attention. So many companies in the world have started integrating the self-managing philosophy into the work teams. In some cases, we have noticed that these teams have not been sufficiently effective, as were the expectations, however, their adaptability to the modern organizational environment (in terms of values, culture, expectations, liberal system, low hierarchy and authority chain just as a formality), has brought positive results. This has also been noted in the studies of the last thirty years.
Despite some findings that create paradoxes in the results of self-managing teams, most studies support the general idea that the outcomes of teamwork are positively influenced by self-managing philosophy. This study suggests similar conclusions. The analysed variables, whether in theoretical or empirical terms, result to be positively related to self-managing philosophy (except for the motivation). This applies in particular to self-managing teams in a start-up setting. A theoretical framework for research development has been created and empirical research has been conducted, which has resulted in a high level of reliability (internal consistency (Cronbach's Alpha) higher than .74, up to .95) and validity (ref: regression and correlation analysis). Finally, by putting the findings of this study in relation to the results of other studies, this research has given a certain contribution in the theory of selfmanaging teams.

After the results and the analysis of regression and correlation, it is evidenced that the self-managing philosophy positively influences the other conceptual variables (except motivation). And finally, the theoretical implications of the findings of the study have come out, which in all cases coincide with most of the findings of previous studies, by reinforcing them. On the other hand, most of the hypotheses raised are tested positively.

In conclusion, a summary of the study can be done on these points:

- Start-up entrepreneurial teams are a suitable model for conducting analysis in the perspective of self-managing philosophy.

- Self-managing philosophy positively influences job satisfaction and per- 
ceived performance of team members.

- There is no link between the self-managing philosophy and motivation of team members.

- Job satisfaction and motivation are positively correlated with perceived performance.

- There is no relation between job satisfaction and motivation.

- The study supports earlier findings regarding job satisfaction, motivation and performance.
Therefore, we may consider that this study has given a modest contribution to the overall theory of self-managing teams, which provides a good foundation for further research. This paper can also serve as a springboard for scholars focusing on developing research in groups with team features in Kosovo. In the end, this paper suggests that other researches fill the gap that exists between the concept of selfmanaging teams and teams. 4 


\section{RFFERFNCES}

Anderson, D., Rankin, A. \& Diptee, D. D., 2017. Approaches to team performance assessment: a comparison of self-assessment reports and behavioral observer scales. Cognition, Technology \& Work, 19(1), pp. 517-528.

Avdiaj, B., 201\%. Small team effectiveness on decision-making. Prishtina: University of Prishtina.

Avdiaj, B., 2019. Job satisfaction, motivation and performance of teams in self-managing perspective. Prishtina: AAB College.

Barry, B. \&e Stewart, G. L., 1997. Composition, Process, and Performance in Self-Managed Groups: The Role of Personality. Journal of Applied Psychology, 82(1), pp. 62-78.

Campion, M. A., Medsker, G. J. \& Higgs, A., 1993. Relations between work group characteristics and effectiveness: Implications for designing effective work groups. Personnel Psychology, Volume 46, pp. 823-850.

Campion, M. A., Papper, E. M. \& Medsker, G. J., 1996. Relations between work team characteristics and effectiveness: A replication and extension. Personnel Psychology, 49(2), pp. 429-452.

Champoux, J., 2011. Organizational Behavior: Integrating Individuals, Groups and Organizations. 4th ed. Abingdon, Oxon: Taylor\&Francis.

Cohen, S. G. \& Ledford Jr., G. E., 1994. The Effectiveness of Self-Managing teams: A QuasiExperiment. Human Relations, 47(1), pp. 13-43.

Daft, R. L., 2008. Management. 8th ed. Ohio: Thompson Higher Education.

Druskat, V. U. \& Wheeler, J. V., 2004. How to lead a self-managing team. IEEE Engineering Management Review, 32(4), pp. 21-28.

Elloy, D. F., 2005. The influence of superleader behaviors on organization commitment, job satisfaction and organization self-esteem in self-managed work team. Leadership \& Organization Development, 26(2), pp. 120-12\%.

Elmuti, D., 1997. Self-managed work teams approach: creative management tool or a fad?. Management Decision, 35(3), pp. 233-239.

Elmuti, D. \& Kathawala, Y., 199\%. Self-Managing Teams, Quality of Work Life, and Productivity: A Field Study. American Journal of Business, 12(1), pp. 19-26.

Forsyth, D. R., 2010. Group Dynamics. 5th ed. Wadsworth: Cengage Learning.

George, J. M. \&e Jones, G. R., 2011. Understanding and Managing Organizational Behavior. 6th ed. New Jersey: Prentice Hall.

Glassop, L. I., 2002. The organizational benefits of teams. Human Relations, 55(2), pp. 225-249.

Goodman, P. S., Devadas, R. \& Hughson, T. L. G., 1988. Groups and Productivity: Analyzing the Effectiveness of Self-Managing Teams. In: J. C. R. Campbell, ed. Productivity in Organizations. San Francisco: Jossey-Bass, pp. 295-327.

Groeneveld, S. \& Kuipers, B., 2014. Teamwork in the Public Cage: Antecedents of Self-Management of Teams in Public Organizations. Philadelphia, USA, Academy of Management Annual Meeting 2014 (Public and Nonprofit Division).

Hackman, J. R., 1976. The design of self-managing, Connecticut: School of Organization and Management, Yale University.

Hackman, J. R., 1986. The psychology of self-management in organizations. In: M. S. Pallak \&e R. O. Perloff, eds. Pyshcology and work: Productivity, change, and employment. Washington, DC: American Psychological Association, pp. 89-136.

Hackman, J. R. \& Oldham, G. R., 1975. Development of the Job Diagnostic Survey. Journal of Applied Psychology, 60(2), pp. 159-170.

Kirkman, B. L. \&e Shapiro, D. L., 2001. The Impact of Team Members' Cultural Values on 
Productivity, Cooperation and Empowerment in Self-Managing Work Teams. Journal of Cross-Cultural Psychology, 32(5), pp. 597-617.

Kozlowski, S. W. J. \& Bell, B. S., 2003. Work Groups and Teams in Organizations. In: W. C. Borman, D. R. Ilgen \& K. R. J, eds. Handbook of psychology. New York: Wiley, pp. 333-35\%.

Langfred, C. W., 2004. Too Much of a Good Thing? Negative Effects of High Trust and Individual Autonomy in Self-Managing Teams. Academy of Management Journal, 47(3), pp. 385-399.

Langfred, C. W., 2005. Autonomy and Performance in Teams: The Multilevel Moderating Effect of Task Interdependence. Journal of Management, 31(4), pp. 513-529.

Lawrence, P. R. \& Lorsch, J. W., 196\%. Differentiation and Integration in Complex Organizations. Administrative Science Quarterly, 12(1), pp. 1-4\%.

Leach, D. J., Wall, T. D., Rogelberg, S. G. \& R, J. P., 2005. Team Autonomy, Performance, and Member Job Strain: Uncovering the Teamwork KSA Link. Applied Psychology, 54(1), pp. $1-24$.

Manz, C. C. \& Neck, C. P., 1995. Teamthink: beyond the groupthink syndrome in self-managing work teams. Journal of Managerial Psychology, 10(1), pp. 7-15.

Mealiea, L. \&e Baltazar, R., 2005. A Strategic Guide for Building Effective Teams. Public Personnel Management, 34(2), pp. 141-160.

Millikin, J. P., Hom, P. W. \& Manz, C. C., 2010. Self-management competencies in self-managing teams: Their impact on multi-team system productivity. The Leadership Quarterly, 21(5), pp. 687-702.

Muthusamy, S. K., Wheeler, J. V. \&e Simmons, B. L., 2005. Self-Managing Work Teams: Enhancing Organizational Innovativeness. Organization Development Journal, 23(3), pp. 53-66.

Neck, C. P. \& Manz, C. C., 1994. From Groupthink to Teamthink: Toward the Creation of Constructive Thought Patterns in Self-Managing Work Teams. Human Relations, 47(8), pp. 929-952.

Park, R., 2012. Self-managing teams and employee attitudes: the moderating role of capital intensity. The International Journal of Human Resource Management, 23(4), pp. 714-730.

Politis, J. D., 2006. Self-leadership behavioural-focused strategies and team performance. The mediating influence of job satisfaction. Leadership \& Organization Development Journal, 27(3), pp. 203-216.

Price, J. H. \& Murnan, J., 2004. Research Limitations and the nEcessity of Reporting Them. American Journal of Health Education, 35(2), pp. 66-6\%.

Ray, J. J., 1979. A Quick Measure of Achievement Motivation - Validated in Australia and Reliable in Britain and South Africa. Australian Psychologist, 14(3), pp. 337-344.

Renkema, M., Bondarouk, T. \& Bos-Nehles, A., 2018. Transformation to self-managing teams: lessons learned: A look at current trends and data. Strategic HR Review, 17(2), pp. 81-84.

Robbins, S. P. \& Judge, T. A., 2013. Essentials of Organizational Behavior. 12th ed. New Jersey: Pearson Education, Inc..

Schermerhorn Jr., J. R., 2014. Exploring Management. 4th ed. New Jersey: John Wiley \&e Sons, Inc..

Schermerhorn Jr., J. R., Hunt, J. G., Osborn, R. N. \& Uhl-Bien, M., 2010. Organizational Behavior. New Jersey: John Wiley \& Sons, Inc..

Solansky, S. T., 2008. Leadership Style and Team Processes in Self-Managed Teams. Journal of Leadership \&e Organizational Studies, 14(4), pp. 332-341.

Stephens, J. P. \& Luddy, C. J., 2016. Operationalizing Heedful Interrelating: How Attending, Responding, and Feeling Comprise Coordinating and Predict Performance in Self-Managing Teams. Frontiers in Psychology, Volume r, p. Article 362. 
Tata, J. \& Prasad, S., 2004. Team Self-management, Organizational Structure, and Judgments of Team Effectiveness. Journal of Managerial Issues, 16(2), pp. 248-265.

van der Hoek, M., Groenveld, S. \& Kuipers, B., 2018. Goal Setting in Teams: Goal Clarity and Team Performance in the Public Sector. Public Personnel Administration, 38(4), pp. 472-493.

van der Vegt, G. S., Bunderson, S. \& Kuipers, B., 2010. Why Turnover Matters in Self-Managing Work Teams: Learning, Social Integration, and Task Flexibility. Journal of Management, 26(5), pp. 1168-1191.

Van Mierlo, H., Rutte, C. G., Kompier, M. A. \& Doorewaard, H. A. C. M., 2005. Self-Managing Teamwork and Psychological Well-Being: Review of a Multilevel Research Domain. Group \& Organization Management, 30(2), pp. 211-235.

Viehhauser, A., 2010. Self-managed teams as company structure and its effect on motivation, job satisfaction, empowerment and perceived performance. Växjö: School of Business and Economics at Linnaeus University .

Vragelaar, R. t., 201\%. Identifying factors for successful self-managing teams: an evidence-based literature review. Enschede, The Netherlands, University of Twente.

Wellins, R. S. et al., 1990. Self-directed teams: A study of currenct practice. Pittsburgh: DDI.

Yang, S.-B. \& Guy, M. E., 2011. The Effectiveness of Self-Managed Work Teams in Government Organizations. Journal of Business and Psychology, 26(4), pp. 531-541. 